\title{
Fusiform vertebral artery aneurysms involving the posterior inferior cerebellar artery origin associated with the sole angiographic anterior spinal artery origin: technical case report and treatment paradigm proposal
}

\author{
Kristine Ravina, MD, ${ }^{1}$ Ben A. Strickland, MD, ${ }^{2}$ Robert C. Rennert, MD, ${ }^{3}$ Vance Fredrickson, MD, ${ }^{2}$ \\ Joshua Bakhsheshian, MD, ${ }^{2}$ Mark Chien, BA, ${ }^{1}$ William Mack, MD, ${ }^{2}$ Arun Amar, MD, ${ }^{2}$ and \\ Jonathan J. Russin, MD ${ }^{1,2}$
}

${ }^{1}$ Neurorestoration Center, Keck School of Medicine and 2Department of Neurological Surgery, Keck School of Medicine, University of Southern California, Los Angeles; and 'Department of Neurosurgery, University of California, San Diego, California

\begin{abstract}
Fusiform aneurysms of the vertebral artery (VA) involving the posterior inferior cerebellar artery (PICA) origin are uncommon and challenging. The anterior spinal artery (ASA) commonly originates from a unilateral ramus just distal to the PICA. Occlusion of an unpaired ASA can result in bilateral medial medullary syndrome. The authors propose a treatment paradigm for ASA preservation based on the artery's proximity to fusiform VA aneurysms, and they present 3 representative cases. In the first case, they performed a $\mathrm{V}_{3}$-PICA bypass using an interposition graft and then performed endovascular coil embolization of the parent VA. A complete occlusion of the aneurysm and VA was complicated by ASA thrombosis. The subsequent cases were treated with PICA-PICA bypass and subsequent endovascular embolization of the VA. Filling of the sole angiographic ASA remote from the aneurysm was preserved in both cases. The anatomy of the ASA is the most critical determinant of treatment recommendations for fusiform VA aneurysms involving PICA. When the ASA originates from the aneurysm, proximal occlusion with or without a PICA bypass is suggested. In cases in which the ASA is removed from the aneurysm, the authors recommend revascularization followed by endovascular sacrifice. When the aneurysm is immediately adjacent to the ASA, revascularization and open trapping should be considered.
\end{abstract}

https://thejns.org/doi/abs/10.3171/2018.5.JNS18681

KEYWORDS anterior spinal artery; cerebral aneurysm; medullary infarct; posterior inferior cerebellar artery; vascular disorders; vertebral artery; surgical technique

$\mathrm{F}$ USIFORM aneurysms are typically the result of atherosclerosis or dissection. The reported incidence is less than $0.1 \%$ of all intracranial aneurysms. ${ }^{2,3,5,29}$ Fusiform aneurysms are most commonly found in the vertebrobasilar system. ${ }^{30}$ Approximately $10 \%$ of the vertebral artery (VA) aneurysms are fusiform and involve the posterior inferior cerebellar artery (PICA) origin. ${ }^{5,18}$ Fusiform VA aneurysms are often dissecting and present with a high rate of recurrent ischemic stroke and rebleeding after initial rupture, posing a significant mortality risk. ${ }^{3,6,11}$, 17,18,23 These aneurysms present a technical challenge for treatment given their location and high variability in their morphology. It is commonly presumed that the anterior spinal artery (ASA) arises from the fusion of paired rami originating from bilateral intradural VAs just distal to the
PICA origin. ${ }^{5}$ However, a high rate of ASA anatomical variability has been reported, with either predominance of one ramus over the other or sole unilateral ramus of origin..$^{10}$ Occlusion of an unpaired ramus of the ASA causes bilateral medial medullary syndrome characterized by flaccid quadriplegia, bilateral disturbance of deep sensation, hypoglossal nerve palsy, and respiratory failure. ${ }^{12} \mathrm{We}$ here propose a treatment paradigm for ASA preservation based on its proximity to fusiform VA aneurysms.

\section{Clinical Presentation Case 1}

A 44-year-old man was admitted after experiencing an acute-onset headache and loss of consciousness. CT scan-

ABBREVIATIONS ASA = anterior spinal artery; $\mathrm{BTO}=$ balloon test occlusion; $\mathrm{FD}=$ flow diversion; $\mathrm{PICA}=$ posterior inferior cerebellar artery; $\mathrm{VA}=$ vertebral artery. SUBMITTED March 13, 2018. ACCEPTED May 2, 2018.

INCLUDE WHEN CITING Published online October 12, 2018; DOI: 10.3171/2018.5.JNS18681. 

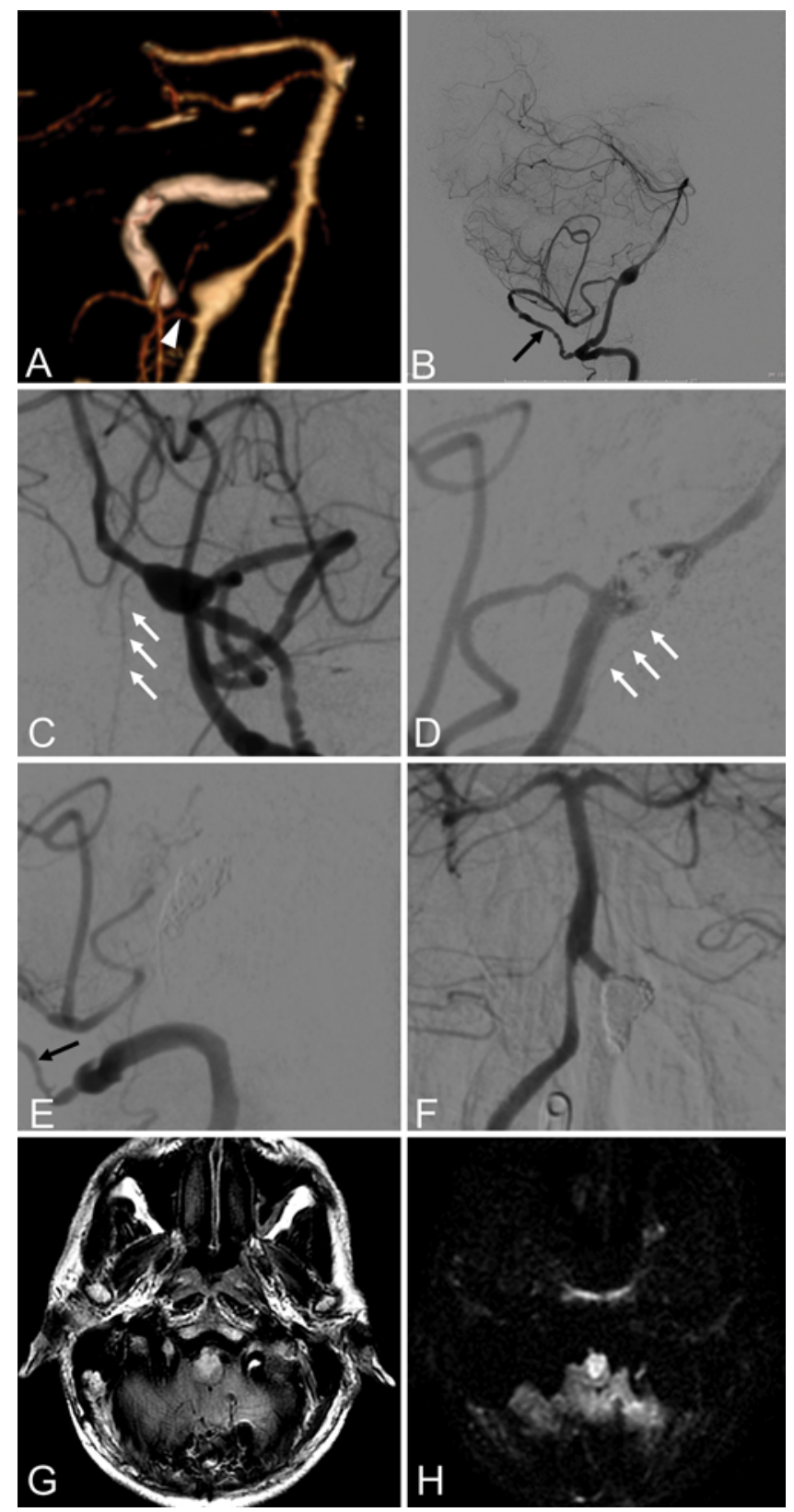

FIG. 1. Case 1: illustrative imaging. A: Preoperative CT angiography (CTA) study with a 3D reconstruction demonstrating a fusiform aneurysm of the left VA involving a PICA origin (arrowhead). B: Postoperative, preembolization catheter angiogram (left VA injection) demonstrating patent ipsilateral $\mathrm{V}_{3}$-PICA bypass (arrow). C: Preembolization catheter angiogram (left VA injection) showing a sole-origin ASA (arrows) distal to the aneurysm. D: Catheter angiogram (left VA injection) following the initial coil embolization, showing a patent ASA (arrows) and VA filling distal to the coil mass. E: Catheter angiogram (left VA injection) following repeated coil embolization, showing filling of the bypass (arrow) and a complete occlusion of the VA. F: Catheter angiogram (right VA injection) following repeated coil embolization, showing no ASA filling. No ASA contribution from the right side can be seen. Postembolization fluid attenuation inversion recovery MRI sequence $(\mathbf{G})$ and diffusion weighted imaging $(\mathrm{H})$ study showing an ASA distribution medullary stroke. ning demonstrated extensive subarachnoid and intraventricular hemorrhage with acute hydrocephalus. A CT angiogram revealed an irregular, dissecting, fusiform aneurysm of the left VA (Fig. 1A). The origin of the left PICA was at the inferior-most portion of the aneurysm and was thought to be at risk of endovascular occlusion. Given the lack of a robust right PICA, a decision was made to proceed with the left $\mathrm{V}_{3}$-left PICA bypass using the descending branch of the lateral circumflex femoral artery (Fig. 1B). After completing the bypass, endovascular coil embolization of the left VA was performed. No ASA contribution from the right VA was identified. The ASA on the left was identified and was located immediately distal to the aneurysm (Fig. 1C). During coil embolization, it was felt that a large portion of the aneurysm was suitably coiled, and anterograde flow was preserved through the VA and ASA (Fig. 1D). On day 9 postembolization, the patient's neurological condition progressively deteriorated, and an emergency catheter angiography was performed with suspicion of vasospasm. Rostrocaudal enlargement of the aneurysm was visualized. Given the risk of repeat rupture, we decided to proceed with repeat embolization proximal to the previously placed coil mass, with parent vessel sacrifice. At that time, it was believed that the ASA, despite its proximity to the aneurysm, would fill via retrograde flow from the contralateral VA. Shortly after completing the embolization, progressive worsening of motor evoked potentials was noted and angiography revealed loss of ASA filling (Fig. 1E and F). The patient suffered bilateral medullary infarction (Fig. $1 \mathrm{G}$ and $\mathrm{H}$ ) and subsequent quadriplegia.

\section{Case 2}

This 40-year-old woman, who had suffered a headache for several days that worsened suddenly and led to a loss of consciousness, was admitted. CT scanning on presentation showed widespread subarachnoid hemorrhage with intraventricular extension. A diagnostic angiogram revealed a fusiform left VA aneurysm involving the PICA origin (Fig. 2A). The treatment recommendation was to perform a PICA-PICA bypass followed by endovascular occlusion of the left VA aneurysm. A sole angiographically documented ASA emanated from the left VA distal to the aneurysm (Fig. 2B). Embolization obliterated the aneurysm and sacrificed the left VA. Postembolization angiography demonstrated retrograde filling of the distal left VA and associated ASA from the right VA (Fig. 2C). Filling of the left PICA through a patent PICA-PICA bypass was also appreciated. Postoperatively, the patient made an uneventful recovery and was discharged on postoperative day 13 .

\section{Case 3}

A 41-year-old man presented with a sudden-onset headache and blurry vision. Subarachnoid hemorrhage resulting from a ruptured dissecting fusiform right VA aneurysm was found and managed conservatively outside of the country. Follow-up angiography 1 month later demonstrated an increase in the size of the aneurysm, with the right PICA originating from the dome of the aneurysm 
(Fig. 3A). The patient was transferred to the United States, and after evaluation we recommended a PICA-PICA bypass followed by coil embolization and sacrifice of the right VA. Angiographically a sole ASA origin was identified distal to the aneurysm (Fig. 3B and C). Following the procedure, the ipsilateral VA was completely occluded (Fig. 3D), and contralateral VA injection revealed brisk filling of the right PICA from the bypass up to its origin, as well as filling of the ASA across the vertebrobasilar junction (Fig. 3E and F). The patient's recovery was unremarkable, and he was discharged with no neurological deficits.

\section{Discussion}

The ASA originates from a single or paired rami branching off of the VAs and supplies the lower two-thirds of the medial medulla and $75 \%$ of the spinal cord. ${ }^{5,10}$ Anatomical variation characterized by the presence of single ASA is not uncommon., ${ }^{5,10}$ The ASA typically originates from the intradural VA, approximately $9 \mathrm{~mm}$ distal to the PICA origin. ${ }^{5}$ The location of the ASA with respect to VA aneurysms and the PICA is not generally a point of emphasis. Our case illustrations underscore the importance of the sole ASA anatomical relation to VA aneurysms.

The ideal treatment for fusiform aneurysms is to completely isolate them from the circulation while preserving flow to parent vessel branches. Surgical treatment-proximal clip ligation, trapping, reconstruction, and/or microvascular bypass - has classically been a method of choice for posterior circulation fusiform aneurysms. Some of these strategies achieve exclusion of the aneurysm from the circulation, while others depend on flow reversal to decrease the risk of future rupture. Endovascular treatments, including parent vessel coil embolization, stenting, stentassisted coiling, and flow diversion (FD), have recently emerged as alternatives to open surgery. ${ }^{1,3,9,19,25}$ FD represents a particularly promising treatment option in the case of unruptured fusiform VA aneurysms. Li et al. used computational fluid dynamics to model hemodynamic changes following FD in fusiform VA aneurysms. ${ }^{19}$ They found that these aneurysms can be treated with FD without significantly affecting the blood flow in major branch vessels such as the PICA. Additional reports utilizing FD in the posterior circulation have shown good results in carefully selected patients receiving strict antiplatelet therapy.,20,21 However, the location and anatomy of the ASA in the published cases of FD use have not been points of emphasis, and, given that the ASA's diameter (range 0.34-1.02 mm) is typically smaller than that of PICA (range 0.61-2.38 $\mathrm{mm}){ }_{10}^{10}$ the concern for thrombosis is heightened. Small vessels, such as the anterior choroidal artery and lenticulostriate perforators, which are close in their diameter to the ASA, have been the subject of recent published case series. ${ }^{7,10,13,15,22,24}$ Factors including the presence of collaterals and the diameter of the parent vessel have been proposed to determine the pressure gradient across the covered vessel, which correlates with its patency rate. ${ }^{7,24}$ While recent studies have increasingly shown good patency rates for anterior choroidal and ophthalmic artery coverage, perforator coverage tends to be more frequently associated with
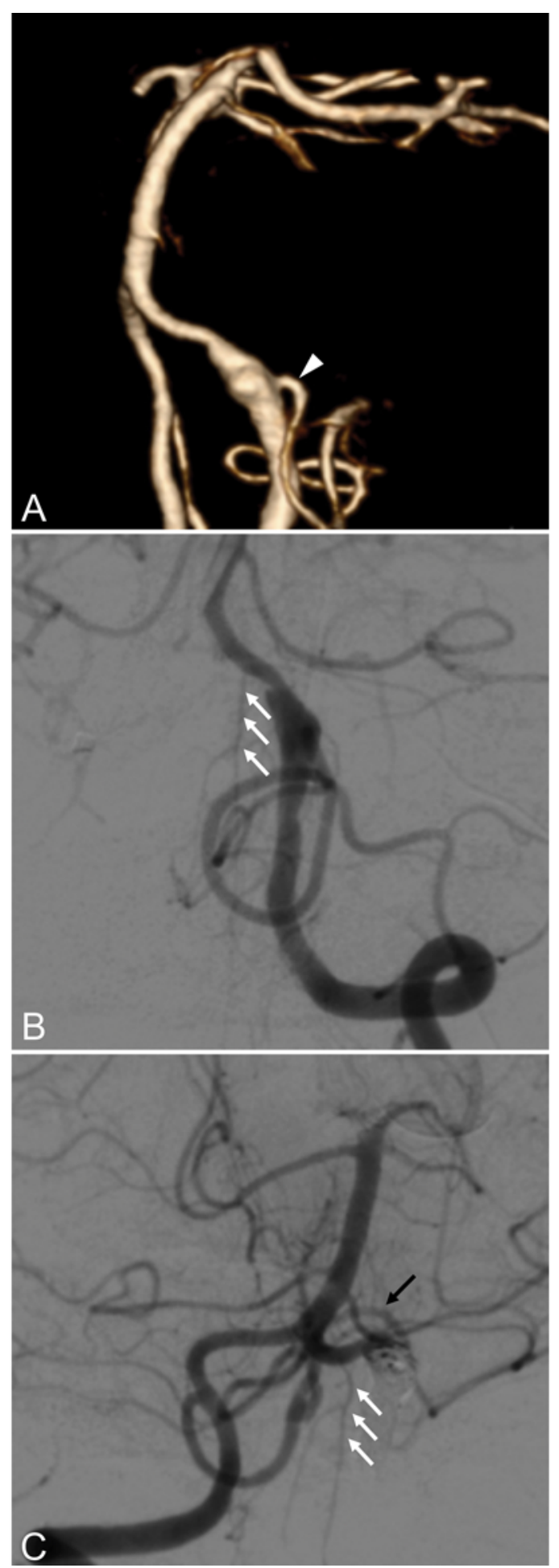

FIG. 2. Case 2: illustrative imaging. A: Preoperative CTA study with a 3D reconstruction demonstrating a fusiform aneurysm of the left VA involving a PICA origin (arrowhead). B: Postoperative, preembolization catheter angiogram (left VA injection) demonstrating a patent PICA-PICA bypass and the sole-origin ASA (arrows). C: Postembolization catheter angiogram (right VA injection) demonstrating retrograde filling of the left distal VA, ASA (white arrows), and PICA (black arrow). No right VA contribution to the ASA can be seen. 

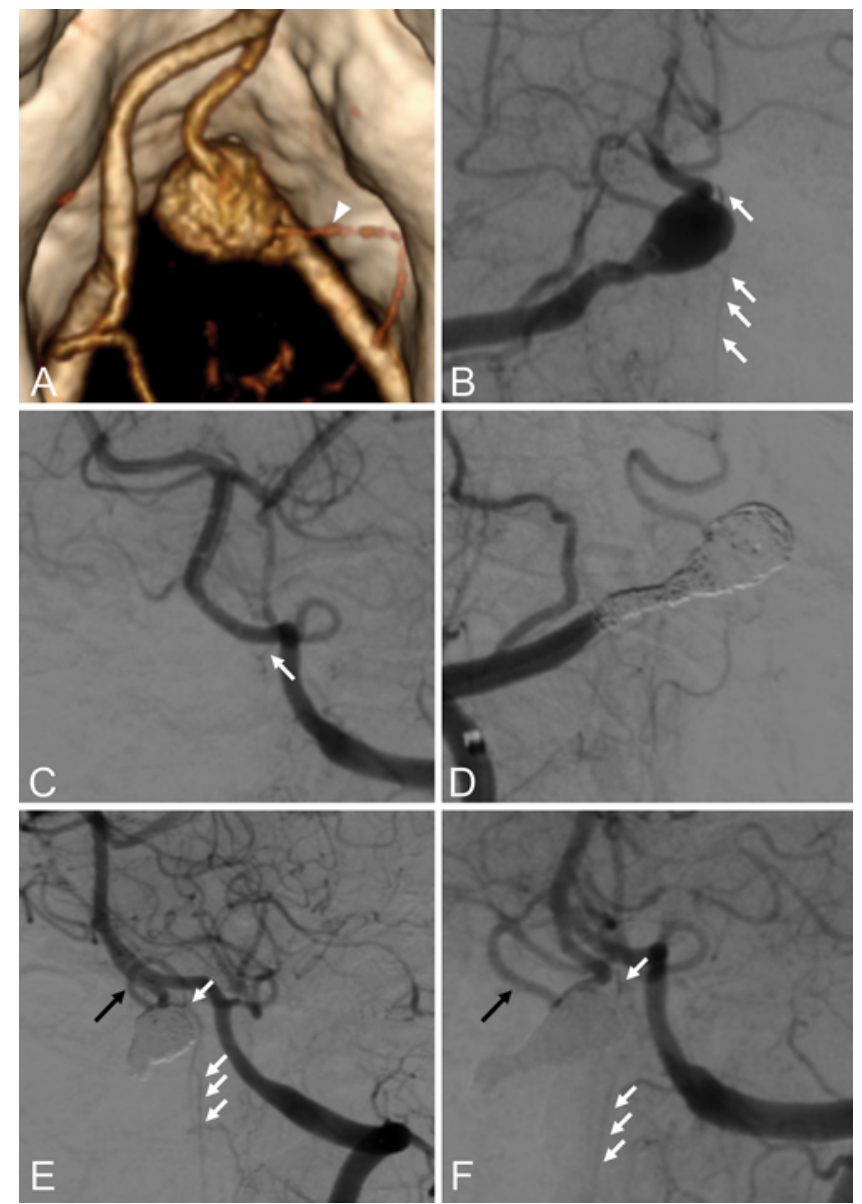

FIG. 3. Case 3: illustrative imaging. A: Preoperative CTA study with a 3D reconstruction demonstrating a fusiform aneurysm of the right VA involving a PICA origin (arrowhead). B: Postoperative, preembolization catheter angiogram (right VA injection) demonstrating patent sole-origin ASA (arrows). C: Postoperative, preembolization catheter angiogram (left VA injection). Note the small brainstem perforator from the distal left VA that is not contributing to the ASA (arrow). D: Postembolization catheter angiogram (right VA injection) showing complete coil occlusion of the VA. E and F: Postembolization catheter angiograms (left VA injection) demonstrating retrograde filling of the ASA (white arrows) and ipsilateral PICA through the bypass (black arrow).

symptomatic occlusion., ${ }^{7,1322,24}$ Collectively, this suggests that FD with dual-antiplatelet therapy is a reasonable option for the treatment of fusiform VA aneurysms when the device will cover the sole angiographic ASA.

Nonsaccular and large aneurysm morphologies, factors associated with incomplete aneurysm occlusion when using $\mathrm{FD}$, are more common in the posterior circulation. ${ }^{4}$ The same factors that promote normal arterial segment branch vessel patency in the case of FD coverage can contribute to persistent aneurysm filling when the branch vessels arise from the aneurysm sac. This has been demonstrated in the literature, with reported aneurysm occlusion rates being lower with FD when branches arise from the aneurysm. ${ }^{16,28}$ Incompletely occluded posterior circulation aneurysms have a relatively poor prognosis with mortality rates as high as $38 \%$ due to subarachnoid hemorrhage, brainstem compression, and/or ischemia. ${ }^{8}$
Considering the aforementioned factors, FD should likely be avoided in cases in which the ASA originates directly from the VA aneurysm. In cases of paired ASAs, the use of FD could be more liberal. When the sole ASA is immediately adjacent to the aneurysm, FD with dualantiplatelet therapy is a treatment option. When there is a contraindication to dual-antiplatelet therapy or when the patient is likely to require a holiday from dual-antiplatelet therapy for additional treatments, FD with coverage of the sole ASA is likely not a favorable treatment option.

When treatment strategies involve VA sacrifice, some surgeons advocate for balloon test occlusion (BTO) prior to the therapeutic VA occlusion to determine hemodynamic tolerance. ${ }^{14,26}$ However, there is very little evidence to show a clinical benefit or reliability for BTO in unilateral VA occlusion. ${ }^{26,27,31}$ Unilateral therapeutic VA occlusion has been proposed to be safe without an antecedent BTO if a contralateral VA is present, patent, and contributes to the vertebrobasilar junction; there is anatomical potential for retrograde filling of the ipsilateral PICA; and there are no brainstem vessels originating from the target segment of the affected VA. ${ }^{31}$ BTO was not used in any of the presented cases since the contralateral VA was adequate, good potential for retrograde filling was rendered angiographically, and the ipsilateral PICA was additionally protected by the bypass. In case 1 , however, the contralateral PICA was unfavorable, and thus an interposition graft was used for the ipsilateral $\mathrm{V}_{3}$-PICA bypass.

\section{Treatment Paradigm}

Our experience has been that a combined open and endovascular approach to ruptured, fusiform VA aneurysms involving the PICA yields optimal results. This experience has also highlighted the importance of ASA anatomy when making treatment recommendations for these complex lesions. With this technical case report, we wish to share our paradigm for treatment of these complex lesions to help other surgeons avoid complications. It is our practice to proceed to the operating room for PICA-PICA bypass or other PICA revascularization when a ruptured, fusiform VA aneurysm involving PICA presents. The patient is then explored angiographically and efforts are made to identify the ASA anatomy. In cases in which no ASA can be visualized, treatment proceeds with embolization of the aneurysm and parent artery. When the ASA is contralateral to or remote from the aneurysm, the same endovascular treatment is recommended (Fig. 4A and B). In cases in which the ASA is immediately adjacent to the aneurysm, open trapping of the aneurysm is considered as it facilitates the best visualization and preservation of the ASA (Fig. 4C and D). If this is deemed unfavorable, proximal VA occlusion is performed, allowing retrograde filling of the aneurysm. If the ASA originates from the aneurysm, proximal occlusion is also our treatment of choice (Fig. 4E and F). If the aneurysmal VA is the sole source of anterograde flow into the basilar artery and the patient lacks significant posterior communicating arteries (Fig. $4 \mathrm{G}$ ), we consider distal revascularization with a superficial temporal artery-superior cerebellar artery bypass followed by the same treatment paradigm used for the ASA (Fig. 4H) versus FD (Fig. 4I). 

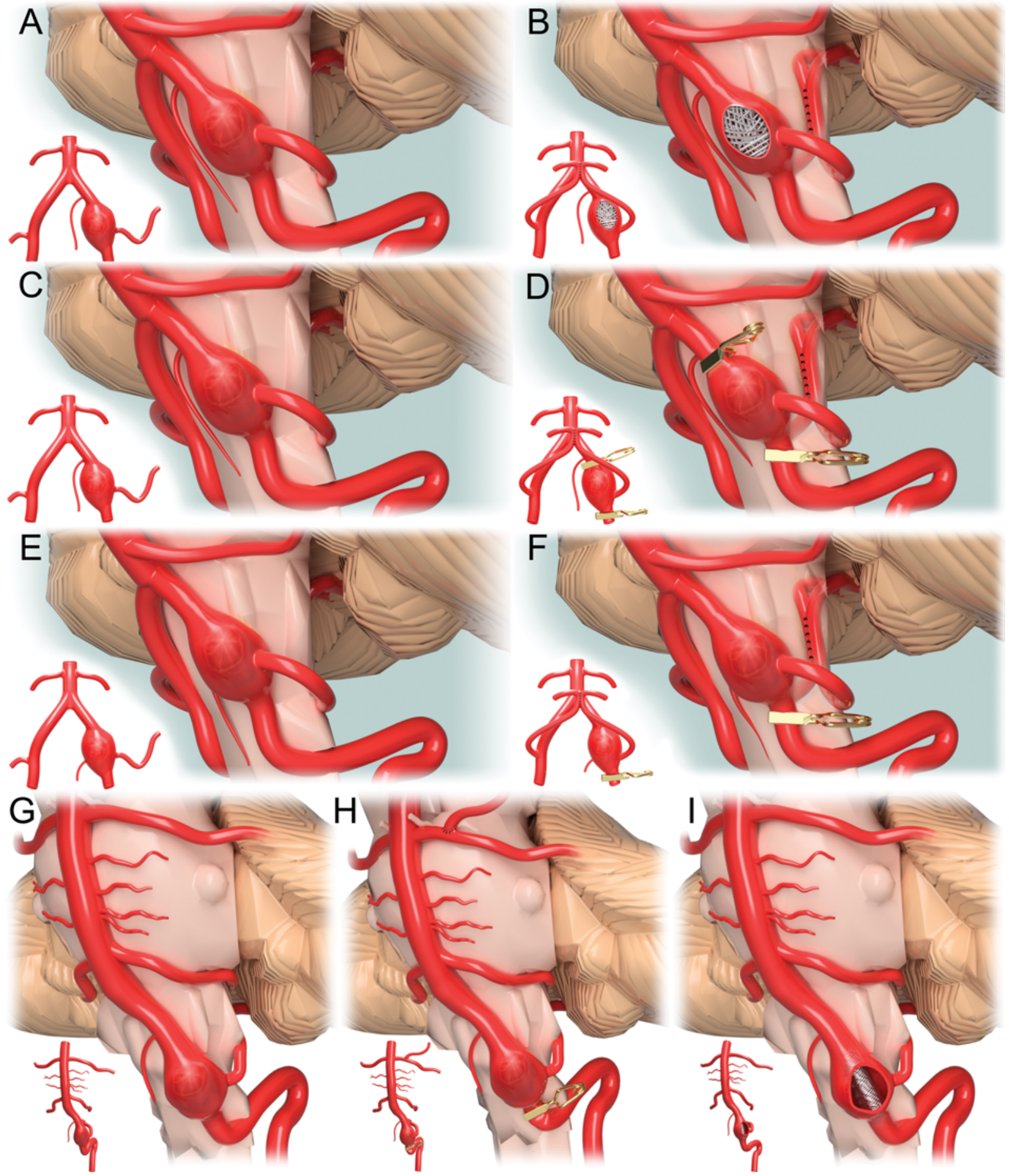

FIG. 4. Schematic illustrations of the proposed treatment paradigm for the ASA preservation based on its proximity to fusiform VA aneurysms. A: Schematic illustration of a fusiform VA aneurysm involving a PICA origin, where the sole-origin ASA is located remotely. B: Treatment of a fusiform VA aneurysm using PICA-PICA bypass and endovascular coil embolization. C: Schematic illustration of a fusiform VA aneurysm involving PICA origin, where the sole-origin ASA is immediately adjacent to the aneurysm. D: Treatment of a fusiform VA aneurysm using PICA-PICA bypass and open trapping. E: Schematic illustration of a fusiform VA aneurysm involving the PICA and a sole ASA origin. F: Treatment of a fusiform VA aneurysm using PICA-PICA bypass and proximal parent vessel clip ligation. G: Schematic illustration of a fusiform VA aneurysm involving a PICA origin in case of an unpaired VA as the single source of flow into the basilar artery. H: Treatment of a single fusiform VA aneurysm using superficial temporal artery-superior cerebellar artery bypass and parent vessel clip ligation. I: Alternative treatment of a fusiform single VA aneurysm using FD stent that avoids coverage of the ASA. Copyright Jonathan J. Russin. Published with permission. 


\section{Conclusions}

Fusiform VA aneurysms involving the PICA origin associated with a sole ASA pose a unique treatment challenge given the potentially devastating consequences of ASA occlusion. Detailed review of the ASA anatomy is a critical consideration when making treatment recommendations.

\section{References}

1. Aihara M, Naito I, Shimizu T, Matsumoto M, Asakura K, Miyamoto N, et al: Predictive factors of medullary infarction after endovascular internal trapping using coils for vertebral artery dissecting aneurysms. J Neurosurg [epub ahead of print August 11, 2017; DOI: 10.3171/2017.2.JNS162916]

2. Anson JA, Lawton MT, Spetzler RF: Characteristics and surgical treatment of dolichoectatic and fusiform aneurysms. J Neurosurg 84:185-193, 1996

3. Awad AJ, Mascitelli JR, Haroun RR, De Leacy RA, Fifi JT, Mocco J: Endovascular management of fusiform aneurysms in the posterior circulation: the era of flow diversion. Neurosurg Focus 42(6):E14, 2017

4. Bender MT, Colby GP, Jiang B, Lin LM, Campos JK, $\mathrm{Xu} \mathrm{R}$, et al: Flow diversion of posterior circulation cerebral aneurysms: a single-institution series of 59 cases. Neurosurgery [epub ahead of print], 2018

5. Bernard G, Bruneau M, Spetzler RF: Pathology and Surgery around the Vertebral Artery. Paris: SpringerVerlag France, 2011

6. Bertalanffy H, Sure U, Petermeyer M, Becker R, Gilsbach JM: Management of aneurysms of the vertebral arteryposterior inferior cerebellar artery complex. Neurol Med Chir (Tokyo) 38 (Suppl):93-103, 1998

7. Bhogal P, Ganslandt O, Bäzner H, Henkes H, Pérez MA: The fate of side branches covered by flow diverters-results from 140 patients. World Neurosurg 103:789-798, 2017

8. Coert BA, Chang SD, Do HM, Marks MP, Steinberg GK: Surgical and endovascular management of symptomatic posterior circulation fusiform aneurysms. J Neurosurg 106:855-865, 2007

9. Dabus G, Lin E, Linfante I: Endovascular treatment of fusiform intracranial vertebral artery aneurysms using reconstructive techniques. J Neurointerv Surg 6:589-594, 2014

10. Er U, Fraser K, Lanzino G: The anterior spinal artery origin: a microanatomical study. Spinal Cord 46:45-49, 2008

11. Flemming KD, Wiebers DO, Brown RD Jr, Link MJ, Nakatomi H, Huston J III, et al: Prospective risk of hemorrhage in patients with vertebrobasilar nonsaccular intracranial aneurysm. J Neurosurg 101:82-87, 2004

12. Gan R, Noronha A: The medullary vascular syndromes revisited. J Neurol 242:195-202, 1995

13. Gascou G, Lobotesis K, Brunel H, Machi P, Riquelme C, Eker O, et al: Extra-aneurysmal flow modification following Pipeline Embolization Device implantation: focus on regional branches, perforators, and the parent vessel. AJNR Am J Neuroradiol 36:725-731, 2015

14. Hamada J, Kai Y, Morioka M, Yano S, Todaka T, Ushio Y: Multimodal treatment of ruptured dissecting aneurysms of the vertebral artery during the acute stage. J Neurosurg 99:960-966, 2003

15. Hussein S, Renella RR, Dietz H: Microsurgical anatomy of the anterior choroidal artery. Acta Neurochir (Wien) 92:1928, 1988

16. Kan P, Srinivasan VM, Mbabuike N, Tawk RG, Ban VS, Welch BG, et al: Aneurysms with persistent patency after treatment with the Pipeline Embolization Device. J Neurosurg 126:1894-1898, 2017

17. Kudo T, Iihara K, Satow T, Murao K, Miyamoto S: Incidence of ischemic complications after endovascular treatment for ruptured dissecting vertebral artery aneurysms. Comparison between those arising proximal to and distal to the origin of the posterior inferior cerebellar artery. Interv Neuroradiol 13 (Suppl 1):157-162, 2007

18. Lehto H, Niemelä M, Kivisaari R, Laakso A, Jahromi BR, Hijazy F, et al: Intracranial vertebral artery aneurysms: clinical features and outcome of 190 patients. World Neurosurg 84:380-389, 2015

19. Li W, Liu J, Zhang Y, Wang K, Tian Z, Zhang Q, et al: Flow diversion and outcomes of vertebral fusiform aneurysms after stent-only treatment: a hemodynamic study. World Neurosurg 107:202-210, 2017

20. Munich SA, Tan LA, Keigher KM, Chen M, Moftakhar R, Lopes DK: The Pipeline Embolization Device for the treatment of posterior circulation fusiform aneurysms: lessons learned at a single institution. J Neurosurg 121:1077-1084, 2014

21. Natarajan SK, Lin N, Sonig A, Rai AT, Carpenter JS, Levy EI, et al: The safety of Pipeline flow diversion in fusiform vertebrobasilar aneurysms: a consecutive case series with longer-term follow-up from a single US center. J Neurosurg 125:111-119, 2016

22. Neki H, Caroff J, Jittapiromsak P, Benachour N, Mihalea C, Ikka L, et al: Patency of the anterior choroidal artery covered with a flow-diverter stent. J Neurosurg 123:1540-1545, 2015

23. Peerless SJ, Hernesniemi JA, Gutman FB, Drake CG: Early surgery for ruptured vertebrobasilar aneurysms. J Neurosurg 80:643-649, 1994

24. Rangel-Castilla L, Munich SA, Jaleel N, Cress MC, Krishna C, Sonig A, et al: Patency of anterior circulation branch vessels after Pipeline embolization: longer-term results from 82 aneurysm cases. J Neurosurg 126:1064-1069, 2017

25. Satow T, Ishii D, Iihara K, Sakai N: Endovascular treatment for ruptured vertebral artery dissecting aneurysms: results from Japanese Registry of Neuroendovascular Therapy (JR-NET) 1 and 2. Neurol Med Chir (Tokyo) 54 (Suppl 2):98-106, 2014

26. Sorteberg A: Balloon occlusion tests and therapeutic vessel occlusions revisited: when, when not, and how. AJNR Am J Neuroradiol 35:862-865, 2014

27. Sorteberg A, Bakke SJ, Boysen M, Sorteberg W: Angiographic balloon test occlusion and therapeutic sacrifice of major arteries to the brain. Neurosurgery 63:651-661, 2008

28. Trivelato FP, Salles Rezende MT, Ulhôa AC, Henrique de Castro-Afonso L, Nakiri GS, Abud DG: Occlusion rates of intracranial aneurysms treated with the Pipeline embolization device: the role of branches arising from the sac. J Neurosurg [epub ahead of print April 6, 2018; DOI: 10.3171/2017.10.JNS172175]

29. Yamaura A: Diagnosis and treatment of vertebral aneurysms. J Neurosurg 69:345-349, 1988

30. Yamaura A, Watanabe Y, Saeki N: Dissecting aneurysms of the intracranial vertebral artery. J Neurosurg 72:183-188, 1990

31. Zoarski GH, Seth R: Safety of unilateral endovascular occlusion of the cervical segment of the vertebral artery without antecedent balloon test occlusion. AJNR Am J Neuroradiol 35:856-861, 2014

\section{Disclosures}

The authors report no conflict of interest concerning the materi- 
als or methods used in this study or the findings specified in this paper.

\section{Author Contributions}

Conception and design: Russin, Ravina, Strickland. Acquisition of data: Russin, Ravina, Strickland, Fredrickson, Bakhsheshian, Mack, Amar. Analysis and interpretation of data: Russin, Ravina, Strickland, Rennert. Drafting the article: Russin, Ravina. Critically revising the article: Russin, Ravina. Reviewed submitted version of manuscript: all authors. Approved the final version of the manuscript on behalf of all authors: Russin. Administrative/ technical/material support: Russin, Chien. Study supervision: Russin.

\section{Supplemental Information}

Previous Presentations

Portions of this work were presented in poster form at the 2017 Congress of Neurological Surgeons Annual Meeting, October 7-11, 2017, Boston, MA.

\section{Correspondence}

Jonathan J. Russin: University of Southern California Neurorestoration Center, The Keck School of Medicine, Los Angeles, CA. jonathan.russin@med.usc.edu. 